\title{
STUDY ON DRIFT BEHAVIOR OF CONTAINER ON APRON DUE TO TSUNAMI-INDUCED INCOMING AND RETURN FLOW
}

\author{
Tomoaki Nakamura ${ }^{1}$, Norimi Mizutani ${ }^{2}$ and Yasuhiro Wakamatsu ${ }^{3}$
}

\begin{abstract}
The drift behavior of a shipping container on an apron resulting from a tsunami-induced incoming flow and subsequent return flow is investigated using hydraulic experiments and numerical simulations. Experimental and numerical results show that the container initially set parallel to a quay wall can fall into the sea when the relative overflow height of an incident tsunami is large regardless of the relative initial position of the container. This suggests that it is not always effective to shelter containers near the seawall before large tsunamis. In addition, it is not evident that the container initially set perpendicular to the quay wall drifts seaward, suggesting that an effective countermeasure would be to store containers on the apron in the cross-shore direction.
\end{abstract}

Keywords: tsunami; shipping container; drift behavior; return flow; hydraulic experiments; numerical simulations

\section{INTRODUCTION}

Tsunami-borne shipping containers are of particular interest to coastal and port engineers when developing countermeasures against tsunami damage. In the 2010 Chilean earthquake tsunami, the first tsunami caused approximately 680 containers stored at the south district of the Talcahuano port, Chile, to drift, $30 \%$ of which finally fell into the sea because of the subsequent return flow (Takahashi et al., 2011). In the 2011 Tohoku earthquake tsunami, approximately 2,000 containers were set adrift in the Sendai port, Japan. Such drifting containers can collide with and destroy port facilities during tsunamiinduced incoming flow. Conversely, containers which fall into the sea because of the return flow, after the incoming flow, can be obstacles for vessels entering and leaving devastated ports.

In the past few years, experimental and numerical studies have investigated the drift behavior of containers during tsunami-induced incoming flow. However, few studies have dealt with containers set adrift by the subsequent return flow. Yeom et al. (2008) carried out hydraulic experiments to investigate the tsunami-induced drift behavior of a container in the presence of structures on an apron, and found that if there was a seawall on the apron, the container could fall into the sea on the return flow. Gotoh et al. (2009) computed the tsunami-induced motion of a container on an apron in the presence of a seawall, using the moving particle semi-implicit (MPS) method, and demonstrated the computational capability of the MPS to predict the motion of the container falling into the sea. However, they did not discuss how the container fell into the sea when subject to the return flow.

In this study, the drift behavior of a container on an apron resulting from a tsunami-induced incoming flow and subsequent return flow is investigated using hydraulic experiments and numerical simulations. In the hydraulic experiments, the drift patterns of the container are examined and discussed in terms of the scale of an incident tsunami and the initial position and angle of the container. In the numerical simulations, the motion of the container observed in the hydraulic experiments is simulated using a three-dimensional coupled fluid-structure-sediment interaction model (Nakamura et al., 2011) to investigate its drift behavior in more detail. Furthermore, effective countermeasures to prevent containers from falling into the sea are discussed on the basis of the experimental and numerical results.

\section{HYDRAULIC EXPERIMENTS}

A series of hydraulic experiments based on the Froude similarity with a length ratio of $1 / 75$ were carried out using a wave flume $(25 \mathrm{~m} \times 2.22 \mathrm{~m} \times 2.0 \mathrm{~m})$ equipped with a piston-type wave generator (maximum stroke: $1.5 \mathrm{~m}$ ) in the Department of Civil Engineering, Nagoya University. As shown in Fig. 1, an impermeable vertical seawall for reflecting an incoming run-up tsunami was fixed to an impermeable horizontal flat apron with a vertical quay wall. A container model was placed on the apron, and a tsunami was generated as a half-sinusoidal wave using the wave generator.

A 40 -ft half-loaded container $(37.8 \mathrm{~g}, 32 \mathrm{~mm} \times 163 \mathrm{~mm} \times 35 \mathrm{~mm})$ and a 40 -ft fully-loaded container $(77.6 \mathrm{~g}, 32 \mathrm{~mm} \times 163 \mathrm{~mm} \times 35 \mathrm{~mm})$ were used as container models. The initial angle of the container with respect to the quay wall, $\theta$, was changed to $0^{\circ}, 30^{\circ}, 45^{\circ}, 60^{\circ}$, and $90^{\circ}$. For $\theta=0^{\circ}$, the distance of the seawall from the quay wall, $x_{W}$, was changed to $0.8 \mathrm{~m}$ and $1.5 \mathrm{~m}$. In addition, the

\footnotetext{
${ }_{1}^{1}$ Institute for Advanced Research, Nagoya University, Furo-cho, Chikusa-ku, Nagoya 464-8601, Japan

2 Department of Civil Engineering, Nagoya University, Furo-cho, Chikusa-ku, Nagoya 464-8603, Japan

${ }^{3}$ Tokyo Civil Engineering Branch, Kajima Corporation, 1-3-1, Motoakasaka, Minato-ku, Tokyo 107-8388, Japan
} 


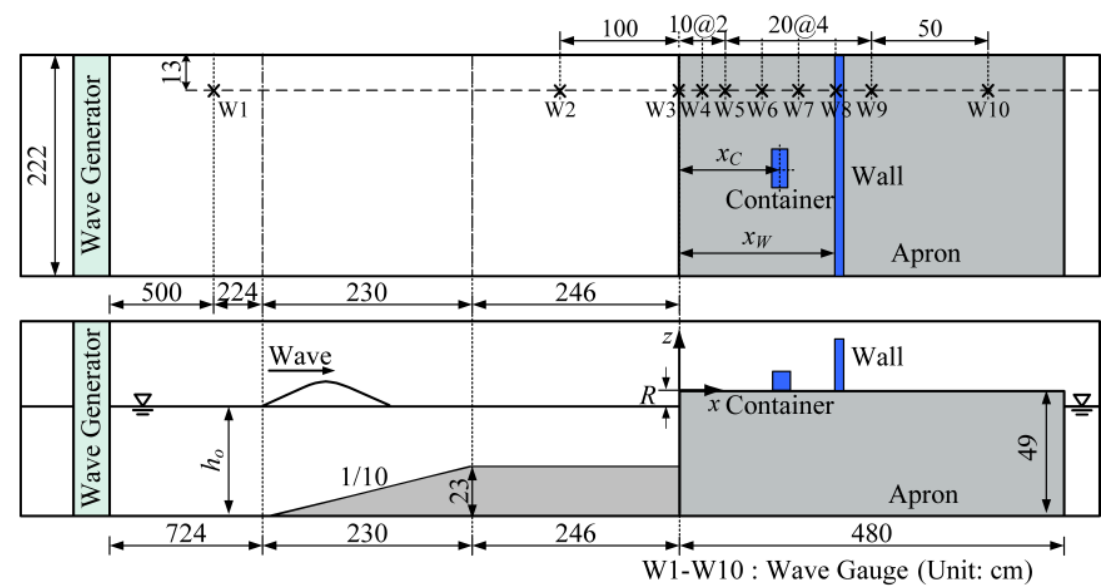

Figure 1. Schematic of the experimental setup.

Table 1. Experimental conditions.

\begin{tabular}{|c|c|c|c|c|c|c|}
\hline Seawall & \multicolumn{3}{|c|}{ Container } & \multicolumn{3}{|c|}{ Tsunami } \\
\hline$x_{W}$ & $x_{C}$ & $\theta$ & Weight & $h_{o}$ & $T$ & $H_{o} / h_{o}$ \\
\hline \multirow{2}{*}{$0.8 \mathrm{~m}$} & $0.2 \mathrm{~m}$ & \multirow{2}{*}{$0^{\circ}$} & \multirow{3}{*}{$37.8 \mathrm{~g}$} & \multirow{3}{*}{$0.46 \mathrm{~m}$} & $6.0 \mathrm{~s}$ & \\
\hline & $0.5 \mathrm{~m}$ & & & & $8.0 \mathrm{~s}$ & 0.07 \\
\hline \multirow{3}{*}{$1.5 \mathrm{~m}$} & $0.5 \mathrm{~m}$ & \multirow{2}{*}{$0^{\circ}$} & & & $10.0 \mathrm{~s}$ & to \\
\hline & $0.8 \mathrm{~m}$ & & \multirow[t]{2}{*}{$77.6 \mathrm{~g}$} & \multirow[t]{2}{*}{$0.48 \mathrm{~m}$} & $12.0 \mathrm{~s}$ & 0.11 \\
\hline & $0.5 \mathrm{~m}$ & $30^{\circ}, 45^{\circ}, 60^{\circ}, 90^{\circ}$ & & & $14.0 \mathrm{~s}$ & \\
\hline
\end{tabular}

distance of the container from the quay wall, $x_{C}$, was changed to $0.2 \mathrm{~m}$ and $0.5 \mathrm{~m}$ for $x_{W}=0.8 \mathrm{~m}$ and to $0.5 \mathrm{~m}$ and $0.8 \mathrm{~m}$ for $x_{W}=1.5 \mathrm{~m}$. For $\theta=30^{\circ}, 45^{\circ}, 60^{\circ}$, and $90^{\circ}$, the values of $x_{W}$ and $x_{C}$ were set at $1.5 \mathrm{~m}$ and $0.5 \mathrm{~m}$. In each case, 14 patterns of tsunami were generated. The offshore still water depth $h_{o}$ was set at $0.46 \mathrm{~m}$ and $0.48 \mathrm{~m}$. The time during which the wave paddle was displaced forward, $T$, was changed at $6.0 \mathrm{~s}, 8.0 \mathrm{~s}, 10.0 \mathrm{~s}, 12.0 \mathrm{~s}$, and $14.0 \mathrm{~s}$, and the relative tsunami height $H_{o} / h_{o}\left(H_{o}\right.$ : offshore tsunami height) was changed from 0.07 to 0.11 . The experimental conditions are summarized in Table 1 .

In each experimental run, the water surface fluctuation in front of the quay wall (W1 to W3; Fig. 1) and the inundation depth on the apron (W4 to W10; Fig. 1) were measured using capacitance-type wave gauges (KENEK: CHT6-40). Simultaneously, the motion of the container was recorded from above the apron using a digital video camera (SONY: HDR-CX550V).

\section{NUMERICAL MODEL}

The three-dimensional coupled fluid-structure-sediment interaction model (Nakamura et al., 2011) was used to analyze the drift behavior of the container in more detail because of the lack of experimental data on the motion of the container except for the recorded videos. The model is composed of a main solver and three modules. The main solver is an extended Navier-Stokes (NS) solver for computing the incompressible viscous air-water multi-phase flow including seepage flow in porous media. The first module is a volume-of-fluid (VOF) module based on the multi-interface advection and reconstruction solver (MARS; Kunugi, 2000) for air-water interface tracking. The second module is an immersed-boundary (IB) module based on the volume force type of IB method (Kajishima et al., 2001) for movable structure motion. The third module is a sediment transport module based on the model of Roulund et al. (2005) for suspended sediment motion and seabed profile evolution due to bed-load and suspended sediment transport. In the model, three modules were connected to the main solver using a two-way coupling procedure implemented at every time step to accurately model and simulate fluid-structure-sediment interaction. In this study, the extended NS solver, the VOF module, and the IB module were employed to compute the motion of the container that considered tsunamicontainer interaction. The detailed explanation of the model can be found in Nakamura et al. (2011).

\section{RESULTS AND DISCUSSION}

\section{Drift Behavior of the Container Parallel to the Quay Wall}

Classification of drift behavior. The drift behavior of the container initially set parallel to the quay wall $\left(\theta=0^{\circ}\right)$ was classified into the following four patterns: 


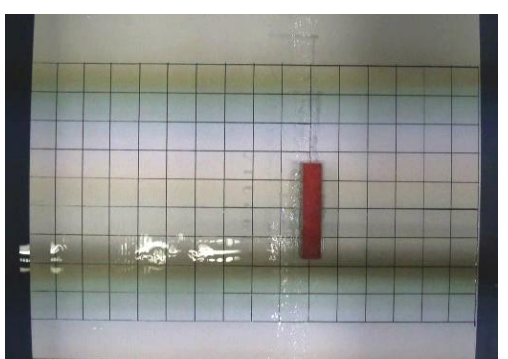

(a) Onset of the drift (0.0 s).

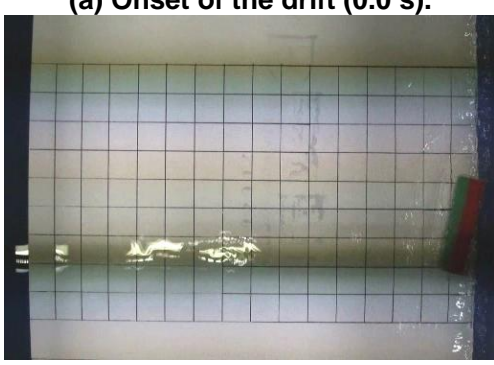

(c) After $0.6 \mathrm{~s}$.

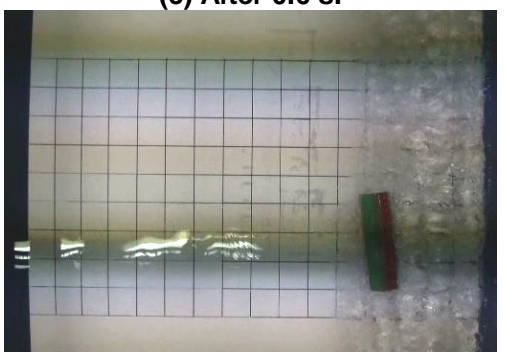

(e) After $1.2 \mathrm{~s}$.

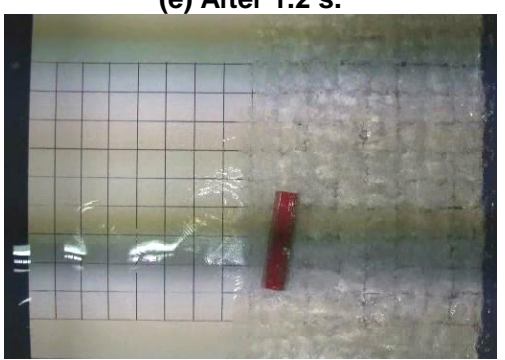

(g) After $1.8 \mathrm{~s}$.

Figure 2. Typical drift behavior of the container for Type $1\left(\theta=0^{\circ}\right.$, half-loaded container, $\left.x_{W}=0.8 \mathrm{~m}, x_{C}=0.5 \mathrm{~m}, h_{o}=0.48 \mathrm{~m}, T=10.0 \mathrm{~s}, H_{o} / h_{o}=0.089\right)$. (b) After $0.3 \mathrm{~s}$.

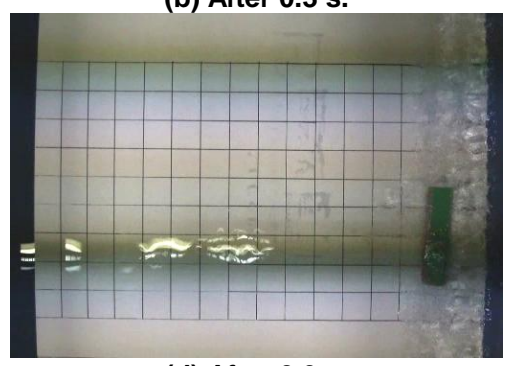

(d) After $0.9 \mathrm{~s}$.

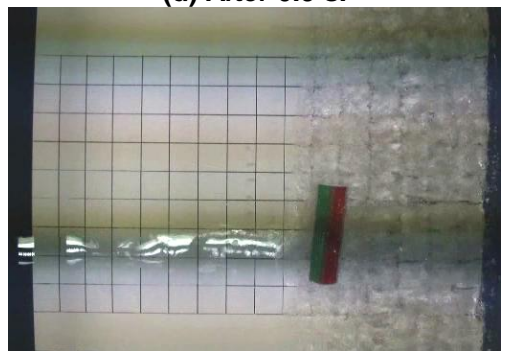

(f) After $1.5 \mathrm{~s}$.

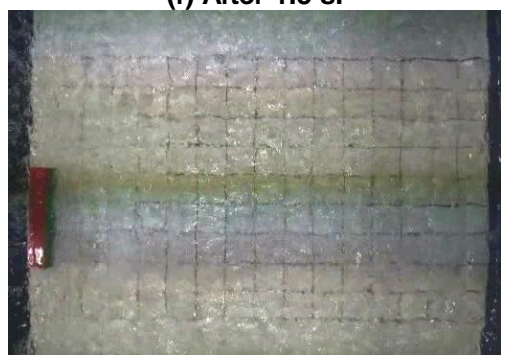

(h) After $2.1 \mathrm{~s}$
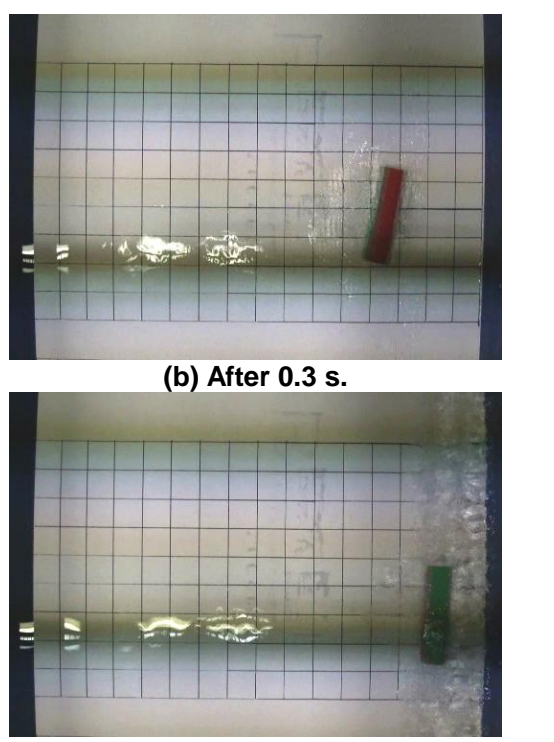

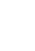




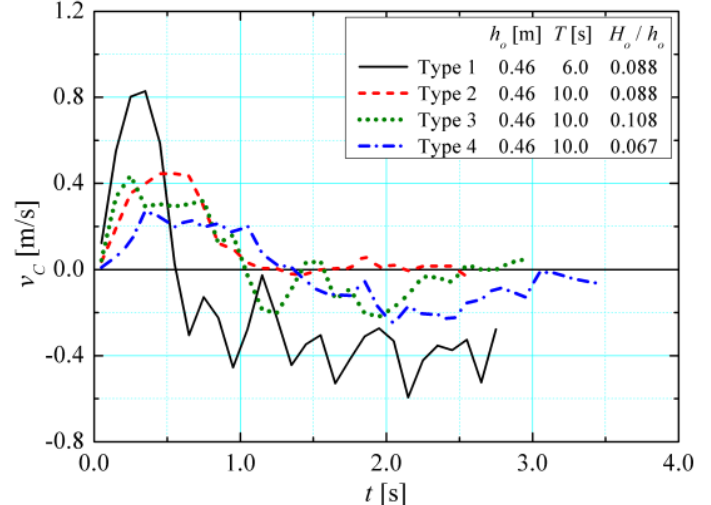

(a) $X_{W}=0.8 \mathrm{~m}, X_{C}=0.5 \mathrm{~m}$.

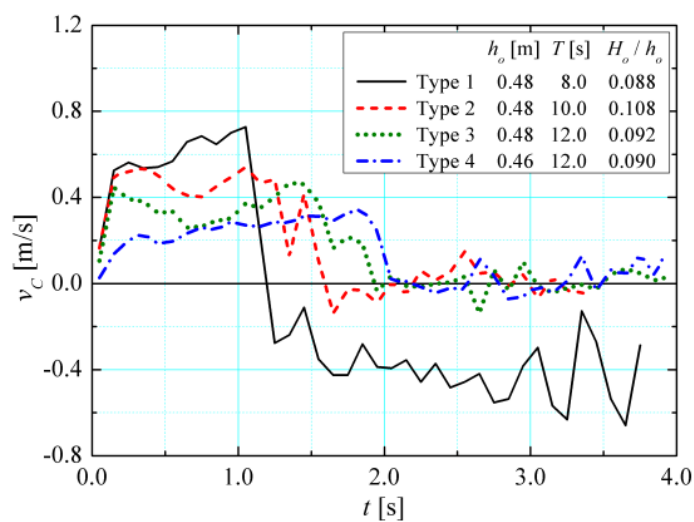

(b) $x_{W}=1.5 \mathrm{~m}, x_{C}=0.8 \mathrm{~m}$.

Figure 3. Cross-shore drift velocity of the container $v_{C}$ for $\theta=0^{\circ}$.
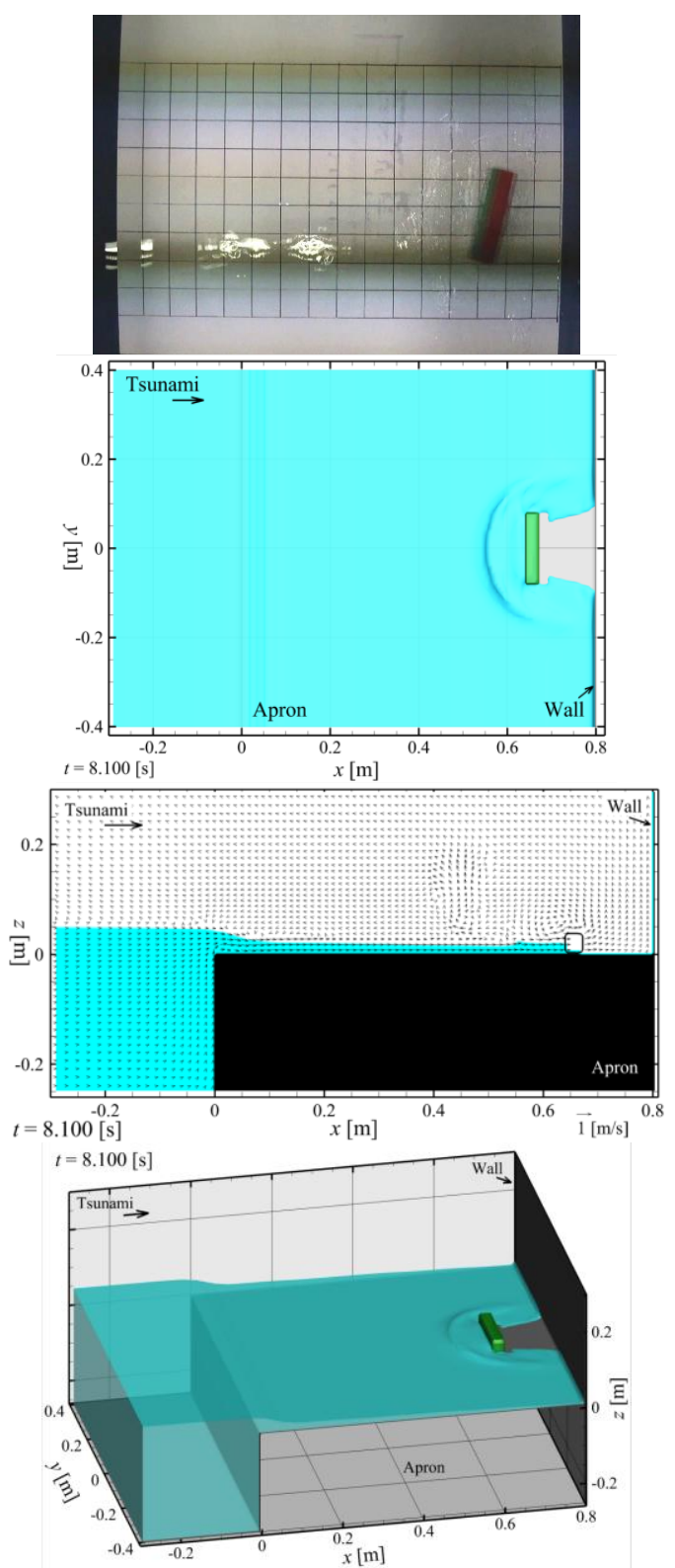

(a) Container drifting landward.
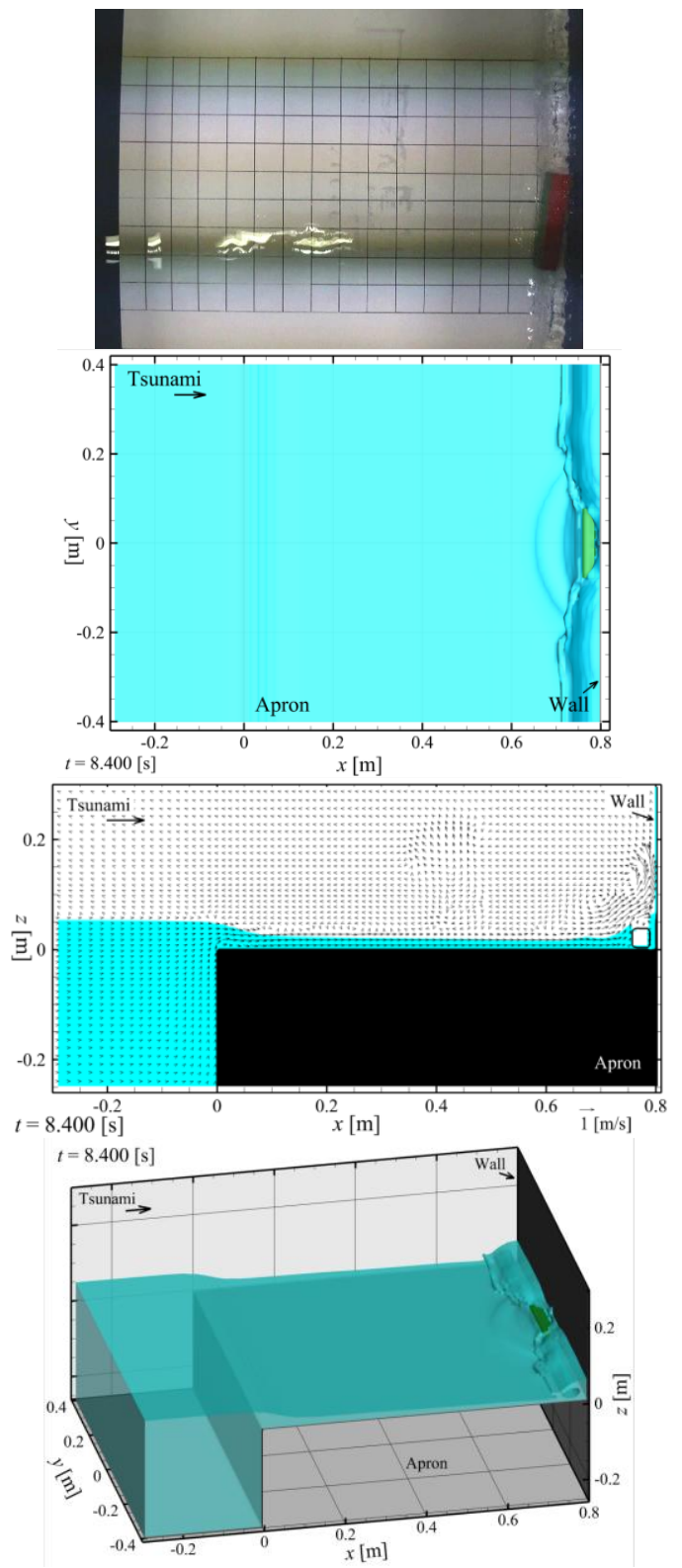

(b) Container drifting close to the seawall.

Figure 4. Drift behavior of the container for Type $1\left(\theta=0^{\circ}\right.$, half-loaded container, $\left.x_{W}=0.8 \mathrm{~m}, x_{C}=0.5 \mathrm{~m}, h_{o}=0.48 \mathrm{~m}, T=10.0 \mathrm{~s}, H_{0} / h_{o}=0.089\right)$. 

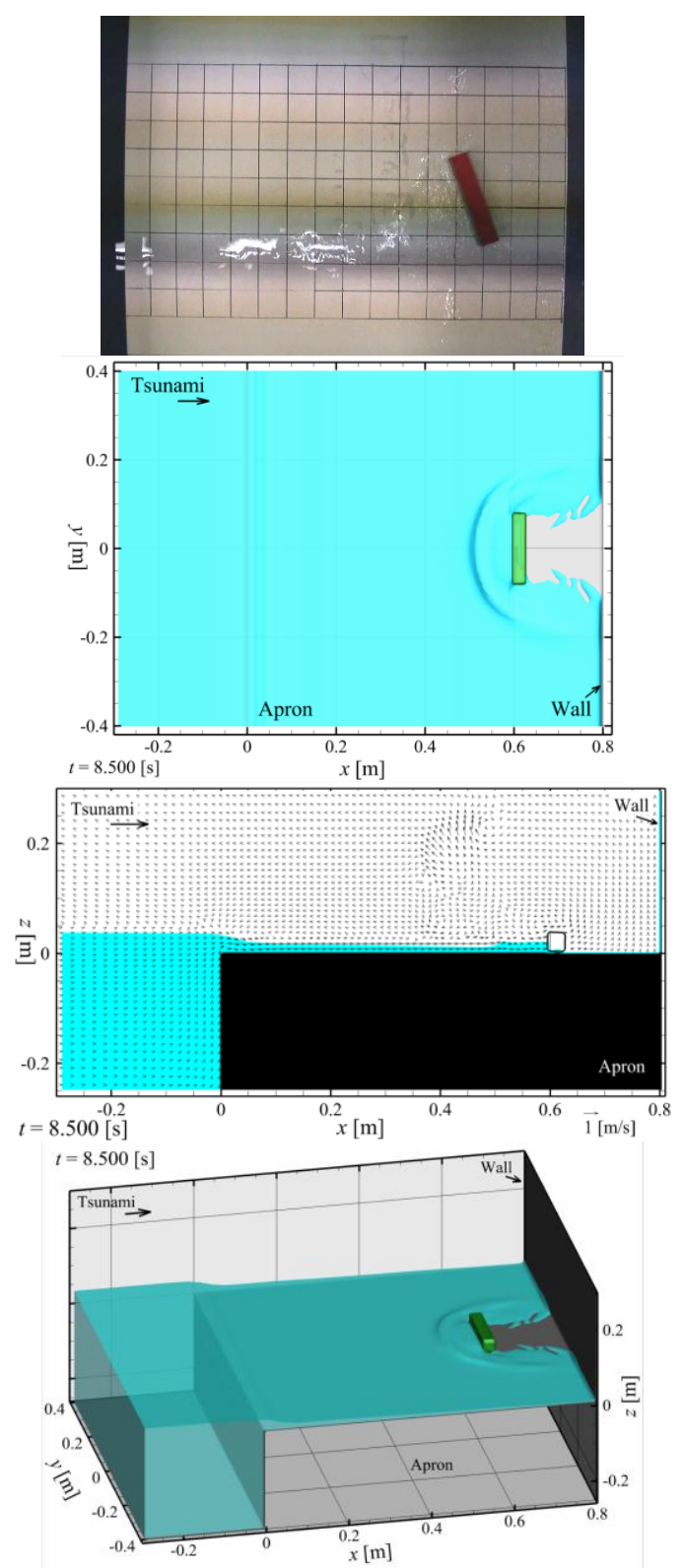

(a) Container drifting landward.

Figure 5. Drift behavior of the container for Type $4\left(\theta=0^{\circ}\right.$, half-loaded container $x_{W}=0.8 \mathrm{~m}, x_{C}=0.5 \mathrm{~m}, h_{o}=0.48 \mathrm{~m}, T=10.0 \mathrm{~s}, H_{o} / h_{o}=0.067$ ).

Figure 3 indicates that the maximum value of $v_{C}$ for Type 1 is the largest regardless of the values of $x_{W}$ and $x_{C}$. In this type, as shown in Fig. 4, the container reached the vicinity of the seawall before increasing the amount of water on the landward side of the container because of the large maximum value of $v_{C}$. Subsequently, the container floated near the seawall as the water level began to rise because of the reflection of the incoming flow, then rode on the tip of the return flow as shown in Figs. 2(d) to 2(h), and finally fell into the sea.

Figure 3 also indicates that the maximum value of $v_{C}$ for Type 2 is the second largest. Following this, the maximum values of $v_{C}$ for Types 3 and 4 are observed in Fig. 3. In Type 4, as shown in Fig. 5, the container did not reach the vicinity of the seawall because of an increase in the amount of water on the landward side of the container. After that, the container began to float after the return flow passed, and accordingly did not ride on the tip of the return flow, unlike Type 1. For this reason, the container stopped on the apron before falling into the sea in Type 4.

Figure 6 shows the diagram of the four drift patterns for $\theta=0^{\circ}$, in which $L$ is the offshore wavelength calculated from $T\left(g h_{o}\right)^{0.5}$ ( $g$ : gravitational acceleration), and $R$ is the freeboard of the apron. Hereinafter, $\left(2 H_{o}-R\right) / L$ is called the relative overflow height of the tsunami, and $\left(x_{W}-x_{C}\right) / L$ 


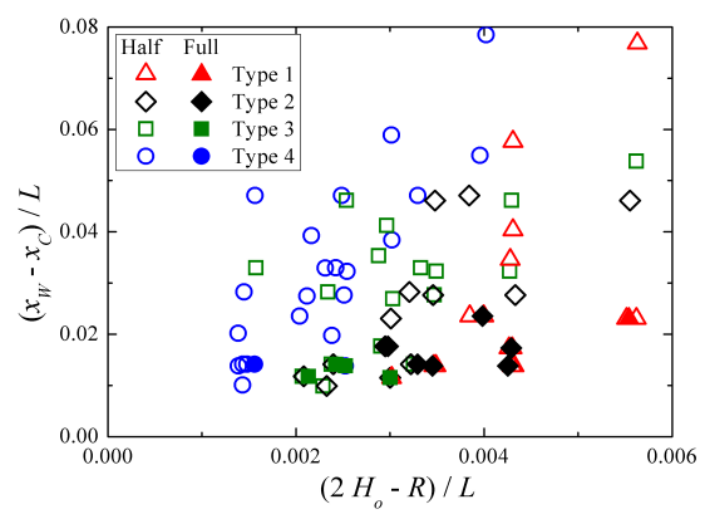

Figure 6. Drift patterns for $\theta=0^{\circ}$.

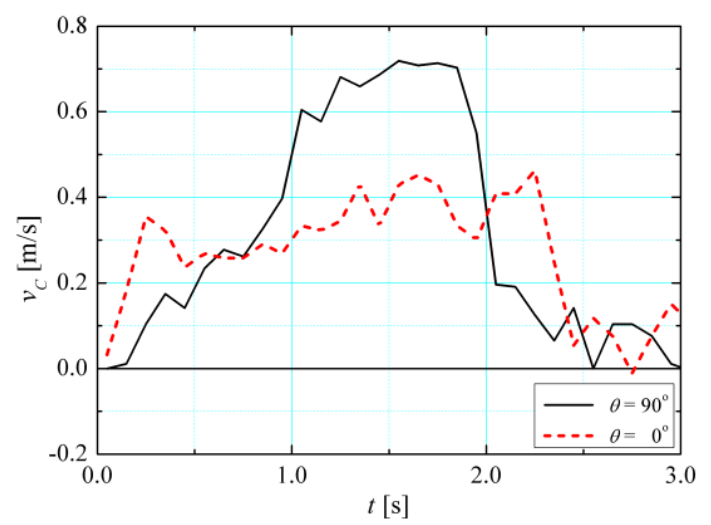

Figure 7. Cross-shore drift velocity of the container $v_{C}$ for $\theta=90^{\circ}$ (half-loaded container, $\left.x_{W}=1.5 \mathrm{~m}, x_{C}=0.5 \mathrm{~m}, h_{o}=0.46 \mathrm{~m}, T=8.0 \mathrm{~s}, H_{o} / h_{o}=0.087\right)$.

is called the relative initial position of the container. As indicated in Fig. 6, the container tended to drift less for small values of $\left(2 H_{o}-R\right) / L$, and accordingly the drift patterns in these cases were classified as Type 4. Figure 6 also shows that the container tended to drift longer with an increase in $\left(2 H_{o}-R\right) / L$. For a further increase in $\left(2 H_{o}-R\right) / L$, the fully-loaded container tended to remain on the apron. However, the half-loaded container fell into the sea in many cases of $\left(2 H_{o}-R\right) / L>0.004$ regardless of the relative initial position of the container $\left(x_{W}-x_{C}\right) / L$, and accordingly the drift patterns in these cases were classified as Type 1. From these results, it is suggested that it is not always effective to shelter containers near the seawall before large tsunamis.

\section{Drift Behavior of the Container Perpendicular to the Quay Wall}

Figure 7 shows a comparison, between $\theta=0^{\circ}$ and $90^{\circ}$, of the time history of the cross-shore drift velocity of the container $v_{C}$. In Fig. 7, the time when the container began to move was defined as $0.0 \mathrm{~s}$, similar to Fig. 3. As indicated in Fig. 7, an increase in $v_{C}$ for $\theta=90^{\circ}$ was slower than for $\theta=0^{\circ}$ because the seaward surface area of the container receiving the tsunami force was small for $\theta=90^{\circ}$ compared with $\theta=0^{\circ}$. Conversely, the maximum value of $v_{C}$ for $\theta=90^{\circ}$ was approximately twice as large as for $\theta=0^{\circ}$ since the landward surface area of the container receiving the resistance force is also small for $\theta=90^{\circ}$. However, there is little difference in the subsequent decrease in $v_{C}$ between $\theta=0^{\circ}$ and $90^{\circ}$. This is because the container in both cases was likely to collide directly with the seawall.

Figure 8 shows the final cross-shore position of the center of gravity of the container $x$ for $\theta=90^{\circ}$. Note that the value of $x$ corresponds to the position at which the container drifting landward stopped because of the return flow and the collision with the seawall, since the container was not observed drifting seaward with the return flow. As indicated in Fig. 8, the final cross-shore position $x$ approaches the seawall $(x=1.5 \mathrm{~m})$ with an increase in $\left(2 H_{o}-R\right) / L$. As a result, it is possible in large tsunamis that containers can collide with the seawall, suggesting an increase in force acting on the seawall from both the tsunami and the collision. It is also suggested that an effective countermeasure would be to store containers on an apron in the cross-shore direction regardless of the scale of tsunamis because the container did not drift seaward as mentioned above. 


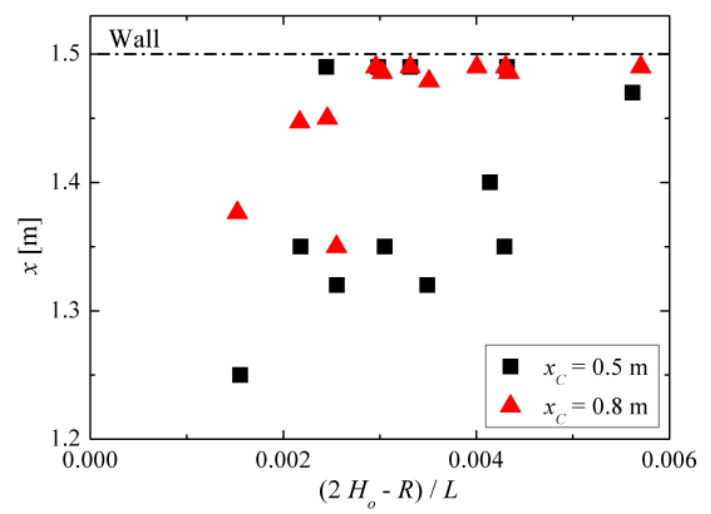

Figure 8. Cross-shore position $x$ at which the container stopped for $\theta=90^{\circ}$ (half-loaded container).

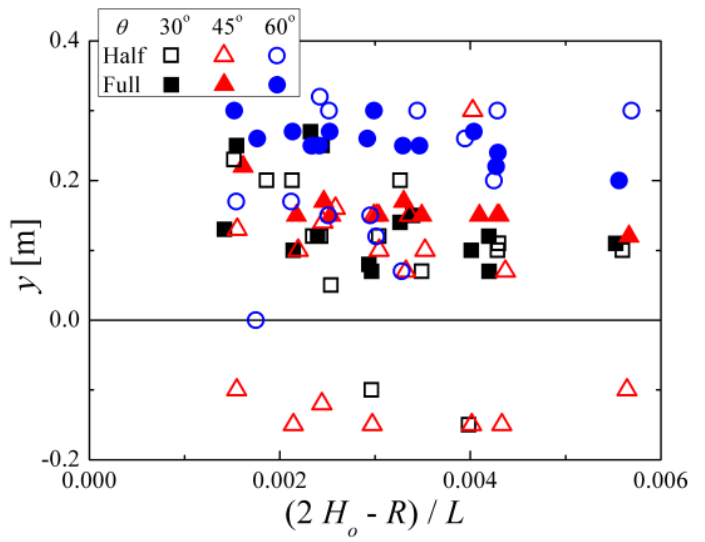

Figure 9. Long-shore position $y$ at which the landward-drift of the container stopped for $\theta=30-60^{\circ}$.

\section{Drift Behavior of the Container Oblique to the Quay Wall}

Figure 9 shows the final long-shore position of the center of gravity of the container $y$ for $\theta=30^{\circ}$, $45^{\circ}$, and $60^{\circ}$. In Fig. 9, the value of $y$ represents the position at which the landward drift of the container stopped resulting from the return flow. Figure 10 shows typical trajectories of the longitudinal axis of the container at a time interval of $0.1 \mathrm{~s}$ for each value of $\theta$.

For $\theta=60^{\circ}$, it is observed from Fig. 10(a) that the container drifted in the positive $y$ direction with the angle of the container almost maintained. As indicated in Fig. 9, the container drifted in the positive $y$ direction in all cases of $\theta=60^{\circ}$. In addition, the value of $y$ increases with an increase in $\left(2 H_{o}-R\right) / L$ for the half-loaded container, while it slightly decreases with an increase in $\left(2 H_{o}-R\right) / L$ for the fullyloaded container. However, the value of $y$ converges to approximately $0.25 \mathrm{~m}$ for large $\left(2 H_{o}-R\right) / L$ regardless of the weight of the container.

Similarly, for $\theta=30^{\circ}$, the container drifted in the positive $y$ direction as shown in Fig. 10(b). As indicated in Fig. 9, the container drifted in the positive $y$ direction in almost all cases of $\theta=30^{\circ}$. In addition, the value of $y$ converges to approximately $0.1 \mathrm{~m}$ with an increase in $\left(2 H_{o}-R\right) / L$. Here, the convergence value of $y$ is slightly smaller compared with $\theta=60^{\circ}$ because the positive $y$ component of the tsunami force acing on the container for $\theta=30^{\circ}$ is smaller than for $\theta=60^{\circ}$.

Conversely, for $\theta=45^{\circ}$, Fig. 9 shows that the container drifted in the positive $y$ direction in approximately half of the cases for the half-loaded container and all of the cases for the fully-loaded container, which was similar drift behavior to $\theta=30$ and $60^{\circ}$. However, the value of $y$ is negative in the remaining cases of the half-loaded container. In these cases, as shown in Fig. 10(c), the container drifted in the positive $y$ direction and then back in the negative $y$ direction.

From these results, it is revealed that it is essential to consider various patterns for the drift of containers where tsunamis act obliquely on them. 


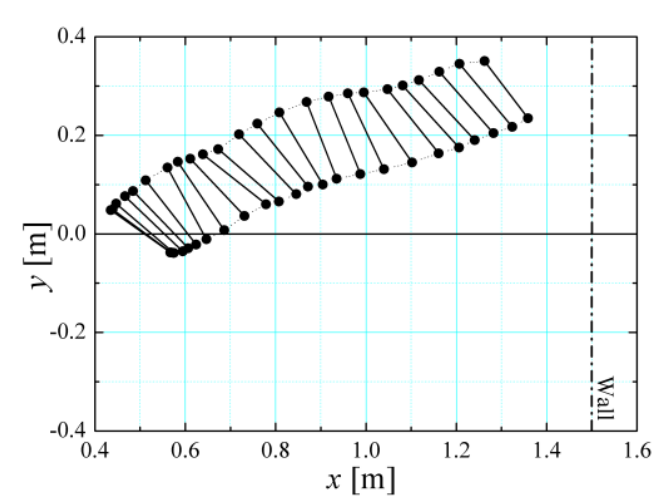

(a) $\theta=60^{\circ}$.

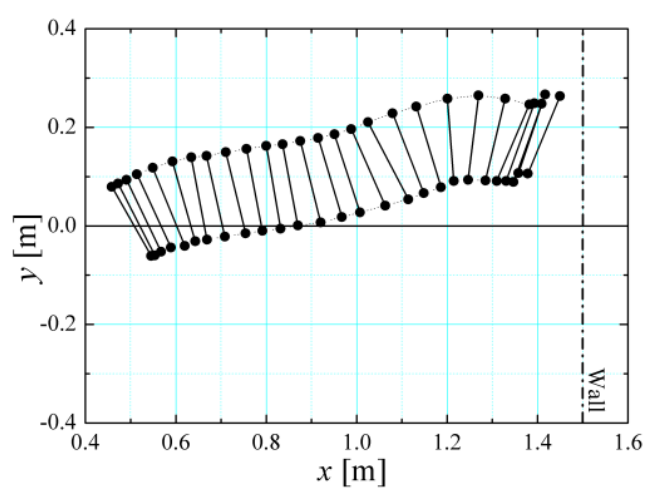

(b) $\theta=30^{\circ}$

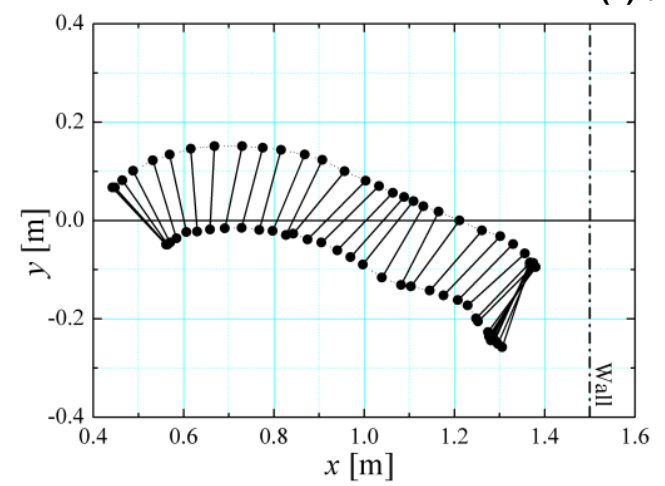

(c) $\theta=45^{\circ}$.

Figure 10. Typical trajectory of the drifting container at a time interval of $0.1 \mathrm{~s}$ (half-loaded container, $\left.x_{W}=1.5 \mathrm{~m}, x_{C}=0.5 \mathrm{~m}, h_{o}=0.46 \mathrm{~m}, T=10.0 \mathrm{~s}, H_{o} / h_{o}=0.088\right)$.

\section{CONCLUDING REMARKS}

In this study, the drift behavior of a shipping container on an apron, due to tsunami-induced incoming flow and subsequent return flow, was investigated using hydraulic experiments and numerical simulations. Models of a 40-ft half-loaded container and a 40-ft fully-loaded container were used, and a half-sinusoidal wave as a tsunami was generated towards them. A three-dimensional coupled fluidstructure-sediment interaction model (Nakamura et al., 2011) was used to analyze the drift behavior of the containers in more detail. The model has the computational capability for simulating the motion of the container that considers the tsunami-container interaction.

The drift behavior of the container initially set parallel to the quay wall was classified into four patterns in terms of the distance of the drift. The results showed that when the relative overflow height of a tsunami is large, the container can fall into the sea regardless of its relative initial position, which suggests that it is not always effective to shelter containers near the seawall before large tsunamis.

The container initially set perpendicular to the quay wall drifted landward because of the incoming flow, but did not drift seaward on the return flow. From this result, it was suggested that an effective countermeasure would be to store containers on an apron in the cross-shore direction regardless of the scale of tsunamis.

The container initially set obliquely to the quay wall drifted only in the positive $y$ direction in many cases. Conversely, the half-loaded container whose initial angle was $45^{\circ}$ with respect to the quay wall drifted in the positive $y$ direction, and then back in the negative $y$ direction in approximately half of the cases. Accordingly, it is essential to consider various patterns for the drift of containers where tsunamis act obliquely on them.

However, the mechanism that determined whether the container fell into the sea was not examined satisfactorily because of the lack of detailed data. To address this issue, further studies need to be conducted to prevent containers from falling into the sea in case of a tsunami.

\section{ACKNOWLEDGMENTS}

The authors are grateful for the financial support of the Japan Science and Technology Agency (JST) under J-RAPID. 


\section{REFERENCES}

Gotoh, H., H. Ikari, K. Tonomo, T. Shibata, T. Harada, and A. Mizoe. 2009. Numerical analysis on drifting behavior of container on apron due to tsunami by particle method. Journal of JSCE, Series B2 (Coastal Engineering), JSCE, 65, 1, 261-265 (in Japanese).

Kajishima, T., S. Takiguchi, H. Hamasaki, and Y. Miyake. 2001. Turbulence structure of particle-laden flow in a vertical plane channel due to vortex shedding. JSME International Journal Series $B$ Fluids and Thermal Engineering, JSME, 44, 4, 526-535.

Kunugi, T. 2000. MARS for multiphase calculation. Computational Fluid Dynamics Journal, 9, 1, IX$563,1-10$.

Nakamura, T., S. C. Yim, and N. Mizutani. 2011. Numerical simulation on local scouring around bottom-mounted movable short cylinder. Proceedings of Coastal Structures 2011, ASCE, C4-087, $12 \mathrm{pp}$.

Roulund, A., B. M. Sumer, J. Fredsøe, and J. Michelsen, 2005. Numerical and experimental investigation of flow and scour around a circular pile. Journal of Fluid Mechanics, 534, 351-401.

Takahashi, S., T. Sugano, T. Tomita, T. Arikawa, D. Tatsumi, H. Kashima, S. Murata, Y. Matsuoka, and T. Nakamura. 2011. Field survey for 2010 Chilean earthquake and tsunami disaster in ports and coasts. Proceedings of 8th International Conference on Urban Earthquake Engineering, 8 pp.

Yeom, G.-S., A. Usami, and N. Mizutani. 2008. Experimental study on behavior of drifted container in front of structure due to run up tsunami and its collision forces. Annual Journal of Civil Engineering in the Ocean, JSCE, 24, 51-56 (in Japanese). 